TecnoLógicas

ISSN-p 0123-7799

ISSN-e 2256-5337

Vol. 21, No. 42, pp. 79-94

Mayo-agosto de 2018

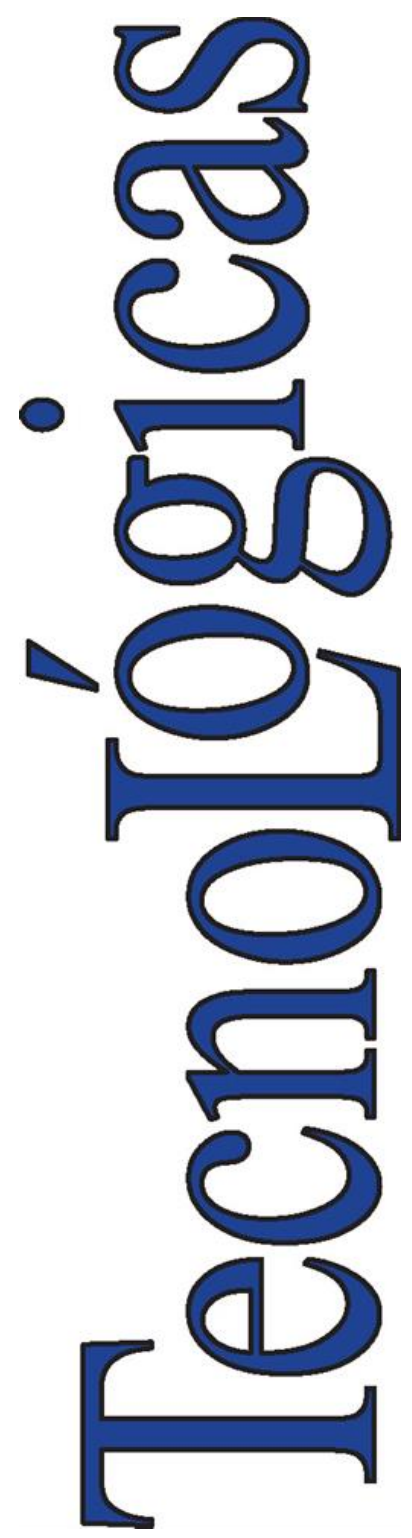

(C) Copyright 2015 por autores y Tecno Lógicas Este trabajo está licenciado bajo una Licencia Internacional Creative Commons Atribución (CC BY)

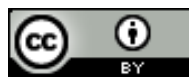

Artículo de Investigación/Research Article

\section{Experimental characterization of compact fluorescent lamps for harmonic analysis of power distribution systems}

\section{Caracterización experimental de lámparas fluorescentes compactas para el análisis armónico de sistemas de distribución de energía eléctrica}

Andrés C. Henao-Muñoz ${ }^{1}$, Javier G. Herrera-Murcia ${ }^{2}$, y Andrés J. Saavedra-Montes ${ }^{3}$

Recibido: 05 de febrero de 2018

Aceptado: 09 de abril de 2018

Cómo citar / How to cite

A. C. Henao-Muñoz, J. G. Herrera-Murcia, y A. J. Saavedra-Montes, Experimental characterization of compact fluorescent lamps for harmonic analysis of power distribution systems. TecnoLógicas, vol. 21, no. 42 , pp. $79-94,2018$.

1 Ingeniero de Control, Departamento de Energía Eléctrica y Automática, Universidad Nacional de Colombia, Medellín-Colombia, achenaom@unal.edu.co

2 PhD en Ingeniería, Magister en Ingeniería con Énfasis en Alta Tensión, Ingeniero Electricista, Departamento de Energía Eléctrica y Automática, Universidad Nacional de Colombia, Medellín-Colombia, jherreram@unal.edu.co

3 PhD en Ingeniería, Magister en Sistemas de Generación de Energía Eléctrica, Ingeniero Electricista, Departamento de Energía Eléctrica y Automática, Universidad Nacional de Colombia, Medellín-Colombia, ajsaaved@unal.edu.co 


\section{Abstract}

The modeling of a compact fluorescent lamp for harmonic analysis under terminal voltage variation is presented in this paper. The compact fluorescent lamp is represented with the diode bridge rectifier model, which is commonly used for harmonic analysis. The set of parameters is estimated for different values of the terminal voltage applied to the lamp. The equations to estimate the parameters and the required measurements to calculate them are presented. To characterize the lamp an experiment is carried out varying the RMS terminal voltage from $10 \mathrm{~V}$ to $131.6 \mathrm{~V}$ and for each terminal voltage value the apparent, real and reactive powers, the power factor, the current and the applied voltage are registered. To validate the model in the range of the terminal voltage, the total harmonic distortion of current calculated with the experimental signal and the total harmonic distortion of current calculated with simulation software are compared. The results show that the compact fluorescent lamp can be represented for one set of parameters in the operation range of the terminal voltage suggested by the manufacture.

\section{Keywords}

Experimental estimation, nonlinear model, compact fluorescent lamps, harmonic studies, terminal voltage variation.

\section{Resumen}

El modelado de una lámpara fluorescente compacta para análisis armónico bajo la variación del voltaje en terminales es presentado en este artículo. La lámpara fluorescente compacta es representada con el modelo de un rectificador tipo puente de diodos, el cual es comúnmente usado para análisis armónico. El conjunto de parámetros es estimado para diferentes valores del voltaje en terminales aplicado a la lámpara. Las ecuaciones para estimar los parámetros y las medidas requeridas para calcularlos son presentadas. Para caracterizar la lámpara un experimento es llevado a cabo variando el voltaje en terminales RMS desde $10 \mathrm{~V}$ hasta $131.6 \mathrm{~V}$ y para cada valor del voltaje en terminales las potencias aparente, real y reactiva, el factor de potencia, la corriente y el voltaje aplicado son registrados. Para validar el modelo en el rango del voltaje en terminales, la distorsión armónica total de corriente calculada con la señal experimental y la distorsión armónica total de corriente calculada con un software de simulación son comparadas. Los resultados muestran que la lámpara fluorescente compacta puede ser representada por un conjunto de parámetros en el rango de operación del voltaje en terminales sugerido por el fabricante.

\section{Palabras clave}

Estimación experimental, modelo no-lineal, lámparas fluorescentes compactas, estudios armónicos, variación del voltaje en terminales. 


\section{INTRODUCTION}

The efficient use of power energy is one of the main objectives of the power industry and particularly the use of compact fluorescent lamps (CFLs) and LED lamps has been a contribution to obtain better energy efficiency. In 2014 the percentage of several lamps used as lighting technology was: $22 \%$ for incandescent light bulbs, $12 \%$ for halogens lamps, $28 \%$ for CFL, 3\% for LED lamps, and 35\% for linear fluorescent tubes. A fall to less than $4 \%$ of incandescent lamps is expected by 2022 [1]. Those incandescent lamps will be replaced by compact fluorescent and LED lamps. The replacement will be driven for the low power consumption of CFLs and LED lamps in contrast with traditional incandescent lamps [1], [2]. However, the massive presence of these highly nonlinear loads in the power distribution systems has generated knew challenges to utilities to keep a good quality of power [3]. Therefore, the big scale use of the lamps has generated an increase in the harmonic distortion of current and consequently, problems related with that phenomenon [4]-[6]. Another problem introduced by CFLs is their low power factor and its consequences as power losses, high voltage regulation, and active power capacity reduction in feeders [7].

To anticipate the problems generated by a massive insertion of small nonlinear loads, several investigations have focused on characterizing and predict the increase of harmonic currents due the CFLs. Some authors have used emulators [8], and others mathematical models [9]-[14]. In [8] the authors recognize the non-linear characteristic of CFLs and the consequently distortion introduced to the power network. In order to study the effects of the CFL non-linear characteristic, the authors propose a memristor emulator circuit, which is able to represent the non-linear characteristic of several CFLs.
Some of the commonly used models to predict the impact of the compact fluorescent lamps over the power distribution systems are the equivalent circuit based on diode rectifier bridge and models in the frequency domain as the model of matrix of coupled admittances. In [15], the authors analyze the impact on current distortion of multiples loads while the feeder length, the supply voltage distortion, and the number of connected CFLs are varied. The analysis was based on simulations using the diode bridge rectifier model of CFLs. In [9] and [11], the authors evaluate the model of matrix of coupled admittances. In [9], the authors propose four simplifications to the model of the matrix of coupled admittance and analyze the precision of the results and the processing time during the simulations. In [11] the equivalent circuit of a CFL is used to derive the equations of the circuit. Later, several methods to estimate the parameters of the circuit are presented. Finally, the authors propose a reduced model and evaluate the impact of the amount of CFLs over the Total Harmonic Distortion (THD) of current through simulations.

In [10] and [13] the equivalent circuit of a CFL is presented. In [10] the model is modified adding a resistance in series with the voltage source increasing the precision of the model when it is compared with the equivalent circuit presented in [11]. Based on this well-known circuit, the authors of [10] and [13] presents an estimation method, which is compared with an estimation method presented in [14]. The method presented in [13] offers better results estimating the parameters.

Despite the large amount of studies in modeling and characterization of CFLs for harmonic analysis, the impact of the changes in the operating point of the voltage source over the THD of current has not been analyzed in all the range of the terminal voltage of the lamps, e.g. in [3] a characterization of the variable waveforms of CFLs is realized for several values of the 
terminal voltage registering the changes of the waveforms and analyzing their nonlinearity; however, the CFLs are not characterized in low values of the terminal voltages.

Studies carried out in [16] and [17] have characterized the impact of the THD of voltage of the distribution system over the THD of current produced by a CFL with electronic ballast, finding that increasing the THD of voltage changes the THD of current; however, an analytical relation between this variables is not defined.

A model commonly reported in literature to represent residential nonlinear loads is an equivalent circuit based in a diode bridge rectifier [2], [14], and [18]. In [14] the authors evaluate the representation of the model for $12 \mathrm{CFLs}$ of different manufacturer. The reported validation errors are lower than $10 \%$ for 11 of the 12 evaluated lamps. However, the lamps were only feeding with their rated voltage. The last results show that model based on diode bridge rectifier is a close representation of the CFLs. For that reason the model based on diode bridge rectifier is selected in this work to represent the CFLs.

The objective of this paper is to model compact fluorescent lamps, from experiments that vary the terminal voltage from zero to higher values than the rated one, for harmonic analysis of distribution systems. The CFL are represented with a model based on diode bridge rectifier, which is commonly reported in the scientific literature as a sufficient representation of CFLs. Consequently, the procedure to estimate the parameters of the model is described in detail. To obtain the required registers by the estimation, an experimental characterization of the load is carried out. During the experiment a CFL is feeding with 32 different values of terminal voltage, which are between $35.7 \mathrm{~V}$ and 131.6 V. This characterization shows the impact generated by the change of the distribution system voltage over the total harmonic distortion of current produced by a CFL. The validity of the model is evaluated comparing the THD of current calculated from the experimental signals versus the THD of current calculated from the software of circuital analysis PSIM ${ }^{\circledR}$ when the model is simulated. The results show that harmonic distortion of current is constant as long as the CFL is powered with a voltage value between the values of the range of operation reported by the manufacturer. Therefore, only one set of parameters can be used to represent the lamp. If a power analysis requires obtaining the harmonic content of a CFL powered with a lower voltage than the range of operation, the parameters of the circuital model should be obtained for the specific value of the applied voltage.

The rest of the paper is organized as follow: Section II describes the methodology to model the CFLs in all the range of their terminal voltage. This section includes the model selection, the process to estimate its parameters, the description of the experiment carried out, and the validation method. Then, Section III presents the characterization of the load, which is intended to obtain the impact that produces the variation of terminal voltage over the THD of current produced by the load. Then, the THD of experimental currents and simulated currents are compared. Finally, the conclusions close the paper.

\section{METHODOLOGY}

The methodology consists in selecting the model based on a diode bridge rectifier to represent the CFLs and a method to estimate its parameters. Later an experiment is carried out varying the terminal voltage of the lamp and its variables are registered in each operating point. Then, the parameters of the model are estimated in each operating point and later the model is simulated in each operating condition through the PSIM ${ }^{\circledR}$ software. Finally, the 
total harmonic distortions calculated from experimental currents are compared with the total harmonic distortions calculated from the simulated currents.

\subsection{Model based on a Diode Bridge Rectifier (DBR) and parameter estimation}

Several residential nonlinear loads are represented by a single phase equivalent circuit of a diode bridge rectifier, see Fig. 1. The CFLs have been closed represented by that model when the lamps are powered in it rated voltage. The model includes in its input an inductor $\mathrm{L}$, which is in series with the rectifier bridge. The rectifier circuit powers a resistance $R$, which represents the power consumed by the load. The capacitance $\mathrm{C}$ is included to reduce the ripple in the resistance. The interaction of these three parameters defines the circuit dynamic and the shape of the current waveform drawing by the circuit.

arameters $L, C$, and $R$ are estimated from the waveform analysis of the source voltage and the current drawn by the circuit. For simulations the circuit should by powered with a source voltage purely sinusoidal. In Fig. 2 there is the comparison of the waveforms of voltage $V s(\theta)$, and current $i(\theta)$. Aditionally, the direct current voltage $\operatorname{Vdc}(\theta)$ is included and the inverse of the source voltage to draw the measures that allow estimating the parameters. The waveforms are presented as a function of $\theta^{\circ}$ given in radians to simplify the analysis. The source voltage is taken as reference and specifically its positive maximum value. The measures highlighted in Fig. 2 are registered, where $B$ is the magnitude of the current pulse measured in A, $a$ is the firing angle of the current pulse in rad, $\gamma_{\max }$ is the angle of the maximum value of the current pulse in rad, and $\delta$ is the fall angle of the current pulse in rad.

Once the values of $B, a, \gamma_{\max }$, and $\delta$ are registered, and additionally the fundamental frequency and the harmonic spectrum of the source voltage and the power consumed by the load, it is possible to estimate the parameters $L, C$, and $R$ of the CFL model. To estimate $L$ and $R$ the rectified voltage $V_{d c}$ should be calculated, therefore the source voltage $V_{s}$ is expressed as the sum of the harmonics that compose it (1).

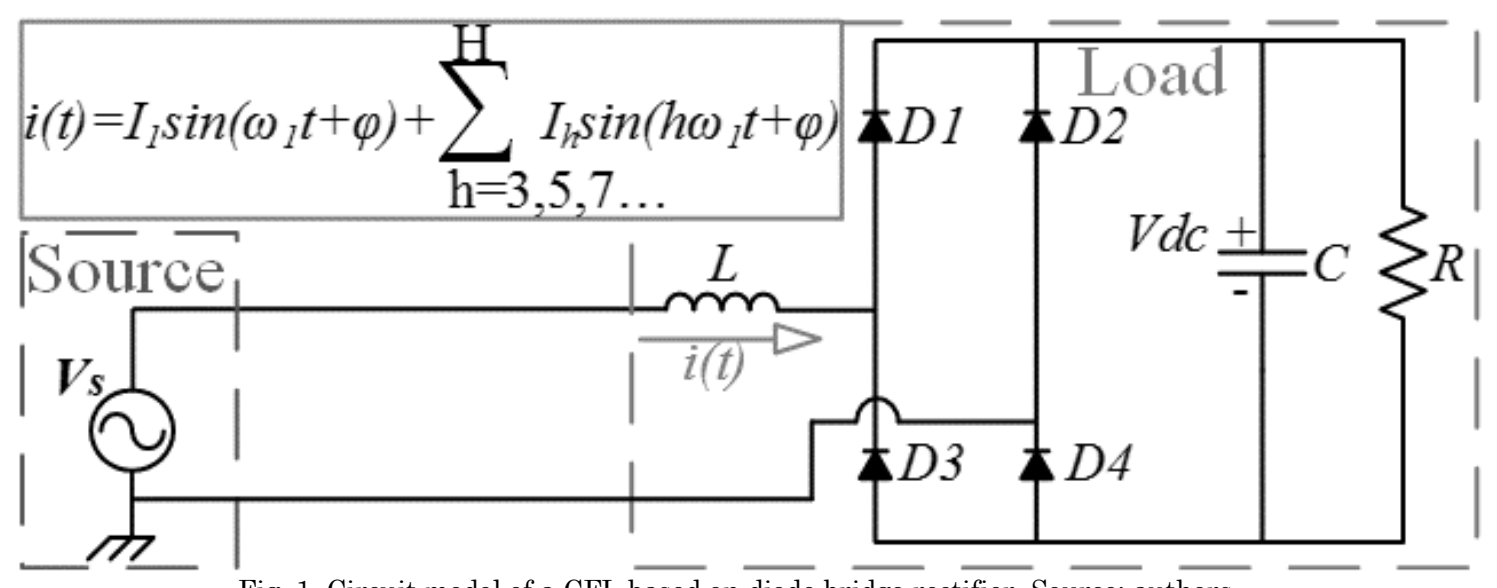

Fig. 1. Circuit model of a CFL based on $\overline{\text { diode }}$ bridge rectifier. Source: authors. 
Experimental characterization of compact fluorescent lamps for harmonic analysis of power distribution systems

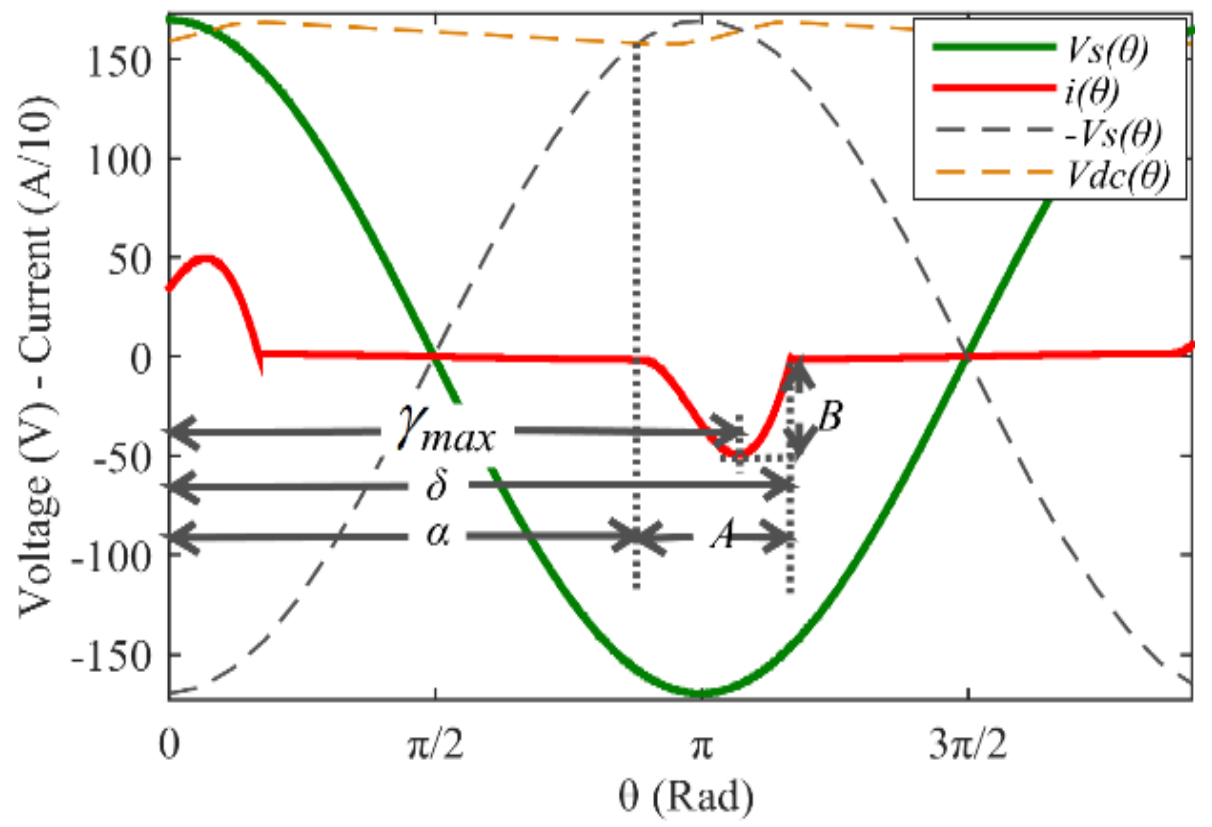

Fig. 2. Comparison of the waveforms of $V_{s}(\theta), i(\theta),-V_{s}(\theta), V_{d c}(\theta)$ to draw the measures $B, a, \gamma_{\max }$, and $\delta$.

Source: authors.

$V_{S}=\sum_{\mathrm{h}=1}^{\mathrm{H}} V_{h} \cos \left(\mathrm{h} \theta+\varphi_{\mathrm{h}}\right)$.

Where, $h$ is the order for each harmonic, $\mathrm{H}$ is the last harmonic present in the spectrum, $\theta=\omega t=2 \Pi f t$, $f$ is the fundamental frequency, and $t$ is the time, $\varphi_{h}$ is the phase angle for each harmonic and $V_{h}$ is the corresponding voltage amplitude.

On the other hand, it is possible to describe the source voltage with a different expression (2), which is derived from the analysis of the equivalent circuit of Fig. 1.

$V_{s}(\theta)=\omega L(\operatorname{di}(\theta) / \mathrm{d} \theta)-V_{d c}$

In Fig. 2 it is observed that $V_{d c}$ and $-V_{s}$ are equals in the radians corresponding with the start of the current pulse $a$, therefore an expression to calculate $V_{d c}$, when $\theta$ $=a$ is obtained (3).

$$
\begin{gathered}
V_{d c}(\alpha)=-V_{s}(\alpha) \\
V_{d c}(\alpha)=-\sum_{\mathrm{h}=1}^{\mathrm{H}} V_{h} \cos \left(\mathrm{h} \alpha+\varphi_{\mathrm{h}}\right)
\end{gathered}
$$

To estimate the inductance L, (2) is integrated between $\alpha$ and $\gamma_{\max }$, where $\alpha \leq \gamma_{\max }$ $\leq \delta$ and the $V_{d c}$ value is assumed constant in time (4).

Because $i(a)=0$, it is possible to solve $i$ $\left(\gamma_{\max }\right)$ from (4) and obtain (5).

$$
\begin{gathered}
\int_{\alpha}^{\gamma_{\max }} \sum_{\mathrm{h}=1}^{\mathrm{H}} V_{h} \cos \left(\mathrm{h} \theta+\varphi_{\mathrm{h}}\right) \mathrm{d} \theta=\int_{\alpha}^{\gamma_{\max }} \omega L(\mathrm{~d} i(\theta) / \mathrm{d} \theta) \mathrm{d} \theta-\int_{\alpha}^{\gamma_{\max }} V_{d c} \mathrm{~d} \theta . \\
\mathrm{i}\left(\gamma_{\max }\right)=\frac{1}{\omega L}\left\{\sum_{\mathrm{h}=1}^{\mathrm{H}} \frac{V_{h}}{h}\left[\sin \left(h \gamma_{\max }+\varphi_{h}\right)-\sin \left(h \alpha+\varphi_{h}\right)\right]+V_{d c}\left(\gamma_{\max }-\alpha\right)\right\}
\end{gathered}
$$


From Fig. 2 it is observed that:

$$
i\left(\gamma_{\max }\right)=\mathrm{B}
$$

Equating (5) and (6), an expression to estimate $L$ is obtained (7).

To estimate the resistance value $R$, again the $V_{d c}$ value is assumed constant in time and equal to the value calculated in (3), and solved from (8).

$$
P_{R}=I_{R} V_{d c}=\frac{V_{d c}}{R} V_{d c}
$$

An expression to estimate $R$ from the power consumed by the load $P_{R}$, is presented as (9).

$$
R=V_{d c}^{2} / P_{R}
$$

To estimate $\mathrm{C}$, the model is simplified neglecting the inductance. So, the ripple of the rectified voltage oscillates between two values, $V_{d c \max }$ and $V_{d c m i n}$. If in some moment the value of $V_{d c}$ falls until $0 \mathrm{~V}_{\mathrm{AC}}$ with the same slope of the oscillation, the decay time would be estimated as $R \cdot C$ seconds, therefore $V_{d c}$ can be expressed with (10).

Finally, solving $C$ from (10) allows estimating the capacitance value from (11).

$$
C=T V_{a c_{\max }} / 4 R\left(V_{a c_{\max }}-V_{d c}\right)
$$

During the estimation of the parameters it is observed that there is a high sensibility in the parameters value depending on the resolution of waveforms in Fig. 2 and consequently in the precision of the measures in the figure.

\subsection{Design of an experiment to characterize a compact fluorescent lamp under the variation of its terminal voltage}

In order to characterize the behavior of a CFL under the variation of the distribution system voltage, and to estimate the parameters of a DBR model that represent the CFL under the same variation, the next experiment is proposed. Two important elements are required to carry out the experiment. An AC voltage supply able to vary the supply voltage from $0 \%$ to $110 \%$ of the nominal voltage of the lamp and a power logger able to register the voltage and current waveforms, its RMS values, harmonic spectrums, THDs, and the fundamental frequency. Those measurements are used to estimate the parameters of the model in any point of operation. Also, the apparent, real, and reactive power, and the power factor should be registered with the power analyzer, and those measurements are used to characterize the behavior of each variable versus the supply voltage variation. Fig. 3. shows the several measurements that are registered with a power logger. In the figure, the measurements correspond to an $85 \mathrm{~V}_{\mathrm{AC}}$. In the first step, the CFL should be powered with $110 \%$ of its nominal voltage and all the variables mention above must be registered. Then, the terminal voltage is reduced in steps of $2 \mathrm{~V}$ until reach $90 \mathrm{~V}$, registering the variables of the CFL in each voltage value. $2 \mathrm{~V}$ were selected as the voltage step in the range of $75 \%$ and $110 \%$ of the nominal voltage because that is the average operation range proposed by the manufacturers of several CFLs. Then, the voltage

$$
\begin{gathered}
L=-\frac{1}{\omega \mathrm{B}}\left\{\sum_{\mathrm{h}=1}^{\mathrm{H}} V_{h}\left[\sin \left(h \gamma_{\max }+\varphi_{h}\right)-\sin \left(h \alpha+\varphi_{h}\right)\right] / h+V_{\mathrm{dc}}\left(\gamma_{\max }-\alpha\right)\right\} \\
V_{d c} \approx\left(V_{d c_{\max }}+V_{d c_{\min }}\right) / 2=V_{a c_{\max }}(1-T / 4 R C)
\end{gathered}
$$


is reduced in steps of $5 \mathrm{~V}$ until the lamp is turned off or an operation failure is reached.

\section{RESULTS AND DISCUSSION}

To characterize a compact fluorescent lamp during its terminal voltage variation, a set of electrical machines is used to carry out the experiment. The set is composed by a synchronous motor and a synchronous generator. The terminal voltage of the synchronous generator is varied with its field current. The field current is produced with a single phase rectifier powered with a variable transformer. See Fig. 4. Before to start the experiment, the no load characteristic of the generator is drawn in order to identify its linear zone and avoid the

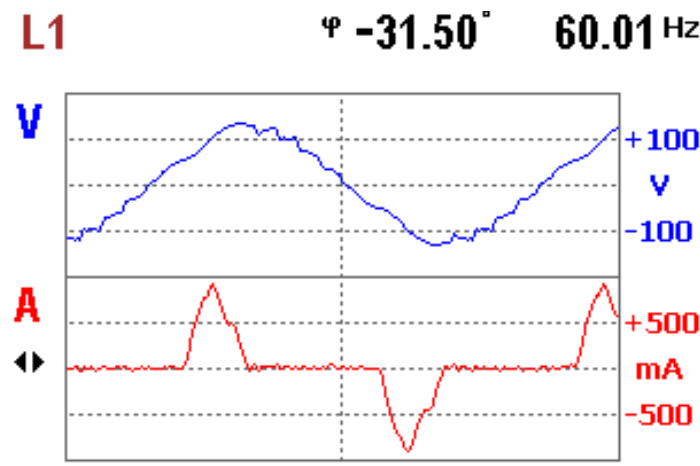

(a)

magnetic saturation effect over the measurements. The CFL is connected to the generator between lines 2 and 3 avoiding the magnetic saturation zone.

Once the voltage source is characterized, the CFL is connected to the generator and the voltage is varied from $131.6 \mathrm{~V}$ until $10 \mathrm{~V}$. The CFL worked until $35.7 \mathrm{~V}$, but data was recorded even when the CFL was off. The variables were registered using the three phase power logger Fluke 1735. It is important to highlight that any power logger with the capacity of register the variables just mentioned, can be utilized. During the experiment more than 32 different voltages were applied to the CFL and the required variables were registered. Figure 5 presents the recorded variables versus the terminal voltage variation.

L1

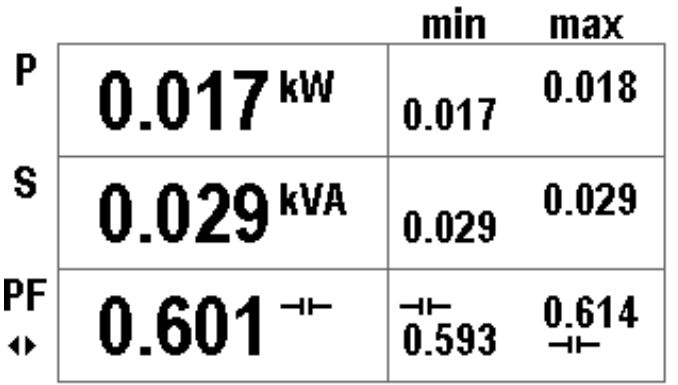

(b)

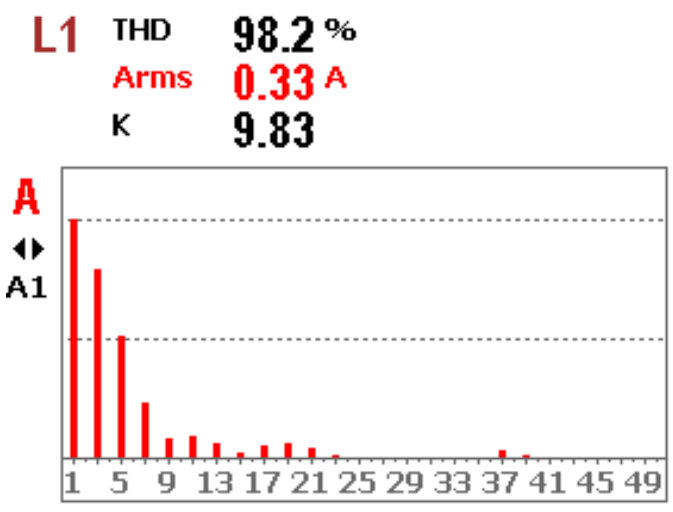

(c)

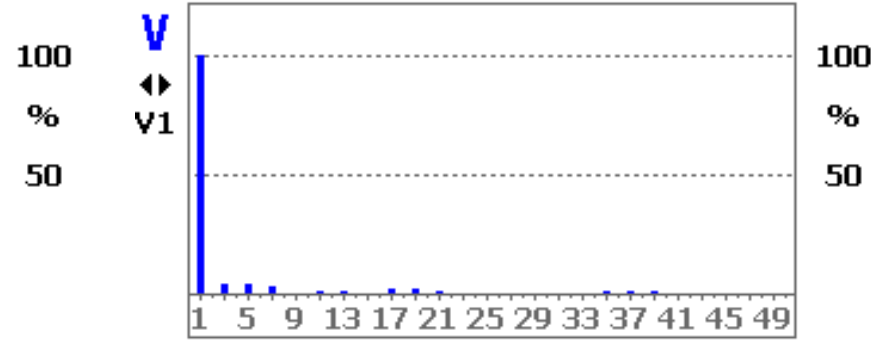

(d)

Fig. 3. Experimental measurements obtained in 85 VAC. a. Waveforms of current, voltage and fundamental frequency b. Power values c. Harmonic spectrum of the current, THD and its RMS value d. Harmonic spectrum of the voltage, THD and its RMS value. Source: Authors' own work. 


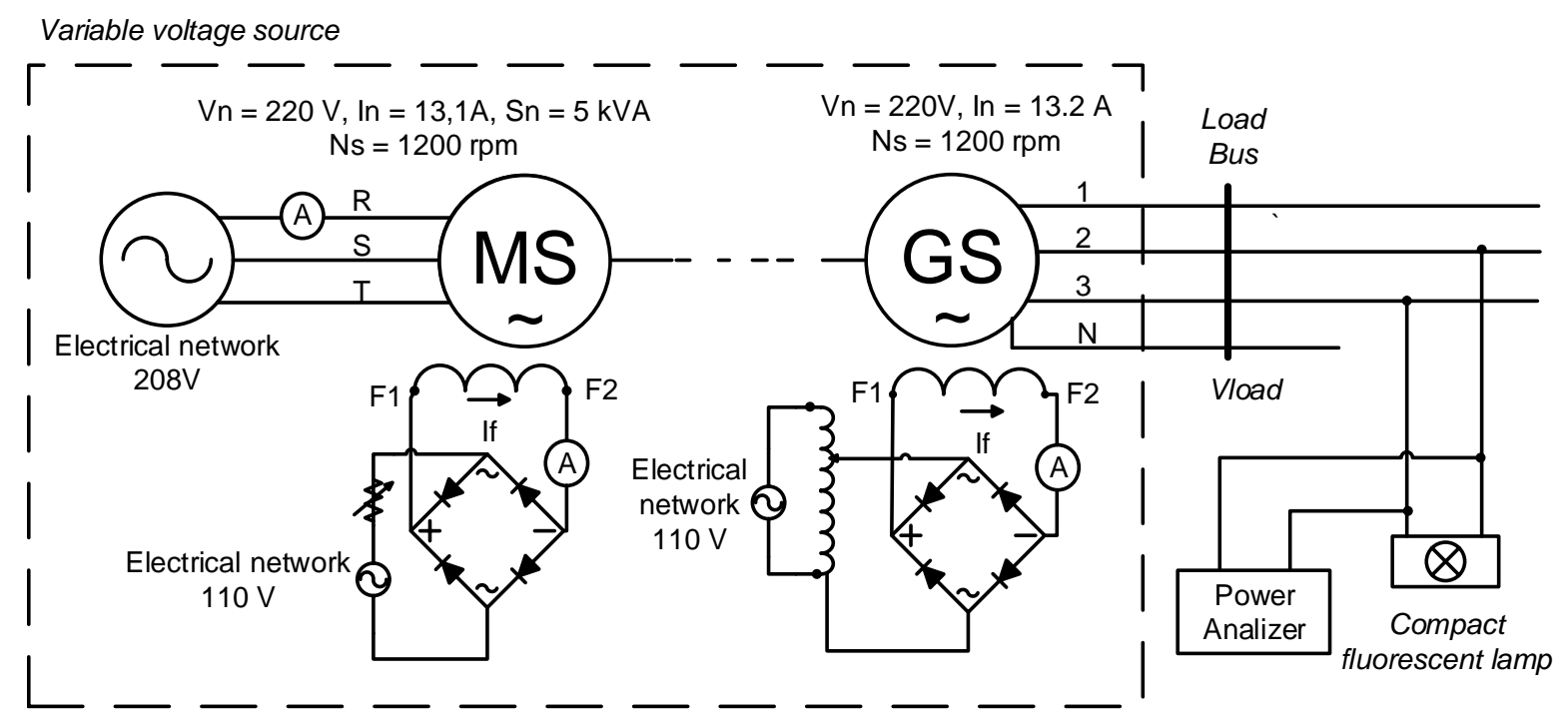

Fig. 4. Electrical diagram of the experimental bench used to vary the terminal voltage applied to the CFL. Source: authors

In Fig. 5 the behavior of apparent, real, and reactive power, power factor, THD of voltage, and THD of current when the terminal voltage is varied, can be observed. The behavior of those six variables characterizes the CFL when its terminal voltage is varied. Apparent and real powers have a similar behavior, both variables increase when the voltage increases. On the other hand, the reactive power absorbed (In this case, the reactive power negative values mean absorbed reactive power) increases in the voltage range between $10 \mathrm{~V}$ and 65 $\mathrm{V}$. The reactive power exhibits a stable value of 5 vars in the voltage range between $116 \mathrm{~V}$ and $130 \mathrm{~V}$. The tendencies of reactive and real powers result in a smoothly power factor variation in the voltage operation range. The THD of current varies from $20 \%$ to $110 \%$ in the whole voltage range, however the THD of current is practically constant in the operation range of the CFL between $90 \mathrm{~V}$ to $130 \mathrm{~V}$. This behavior shows that a CFL has a low effect in a harmonics analysis as long as the terminal voltage is in the operation voltage range.
The behavior of the CFL variables presented in Fig. 5 is validated in contrast with the results reported in [3]. In [3] the authors present the variation of nominal voltage, from $100 \%$ until $50 \%$, of a compact fluorescent lamp while its voltage, current, active power, power factor and THD are recorded. Also, the parameters values of a model that represent the CFL are presented for each voltage value. It is possible to compare the behavior of the variables reported in [3] with the results reported in this work. In both cases the active power is increased proportionally to the increase in the terminal voltage. The power factor variation is small taking the nominal power factor value as a reference.

This situation is reported in both cases; also the power factor variation is close to 0.6 when the terminal voltage is changed in the range of $100 \%$ to $50 \%$ of the nominal voltage. The THD of current reported in both cases presents different behaviors. In [3] the THD of current varies proportionally to the terminal voltage while the measured THD of current reported here, is practically constant in the range $100 \%$ and 
Experimental characterization of compact fluorescent lamps for harmonic analysis of power distribution systems
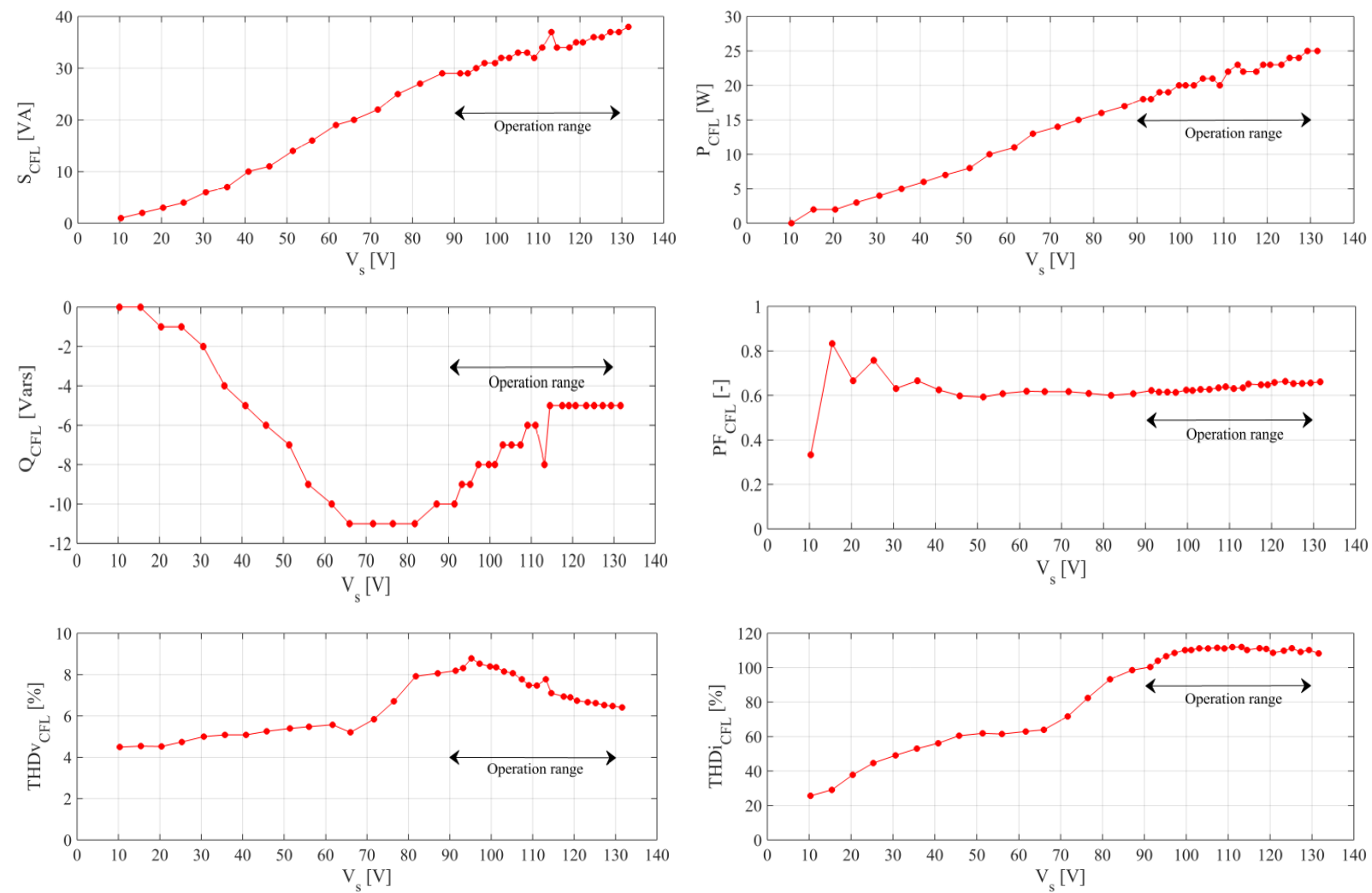

Fig. 5. Variation of apparent, real, and reactive power, power factor, THD of voltage, and THD of current versus the terminal voltage variation. Source: authors

$80 \%$ of the nominal voltage. From $80 \%$ to $50 \%$ of nominal voltage, the THD of current varies proportionally to voltage applied to the CFL. This behavior difference could has its origin in the power interface of each lamp, therefore an opportunity arise in the necessity of carried out experiments where CFL of different manufacturers are powered with a variable terminal voltage from $0 \%$ to $100 \%$. This characterization could offer information to the CFL users, regulators, manufacturers, etc.

On the other hand, to highlight the relationship between the terminal voltage source and the CFL current, in Fig. 6 the waveforms of these two signals are presented. On the bottom left side of Fig. 6, current waveforms corresponding to terminal voltages between $35.7 \mathrm{~V}$ and $87.1 \mathrm{~V}$ are presented. The shapes of those waveforms are different from each other, that difference is also evident in the behavior of THD of current in Fig. 5. Therefore is these type of CFL is summited to voltages below 87.1 V, the current harmonics will vary increasing the risk to find or excite some resonance frequency in the electric system.

The waveforms of the top (left and right) are the corresponding currents to terminal voltages between $91.4 \mathrm{~V}$ and $131.6 \mathrm{~V}$, this is the operation range of the CFL. Those waveforms are slightly different from each other and consequently their THD also vary smoothly as can be seen in Fig. 6

On the bottom right side of Fig. 6 the voltage waveforms of four values are presented. The waveforms are sinusoids that increase the harmonics presence when the voltage value is increased. However the variation of the THD of voltage is in the range of $4 \%$ and $9 \%$, see Fig. 5 . 

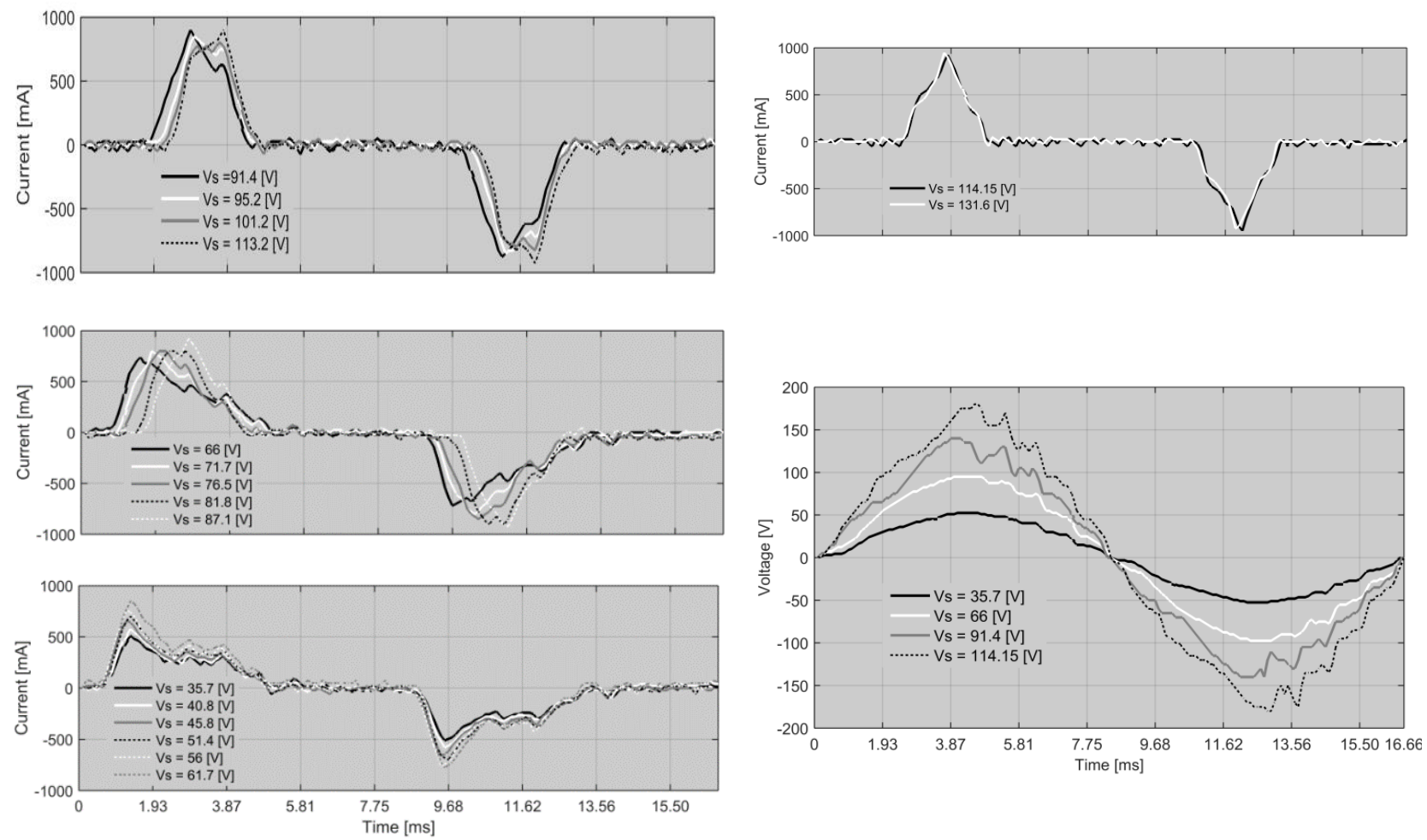

Fig. 6. CFL current and terminal voltage waveforms. Source: authors

\subsection{Parameters of a CFL model for different source voltages}

Because the objective of this work is to model a CFL for harmonic analysis during terminal voltage variation, the procedure described above is used to estimate the parameters $V_{d c}, R, L$, and $C$, for 32 different terminal voltages. The values of the four parameters are plotted versus the terminal voltage to identify tendencies in the parameter values and relationships with variables plotted in Fig. 5, See Fig. 7. $V_{d c}$ has a linear variation respect to terminal voltage in the range of $61.7 \mathrm{~V}$ and 121 $\mathrm{V}$. The parameter $R$ varies with the square of $V_{d c}$, for that reason the range of variation is in the order of $700 \Omega$. The value of the parameter with the smallest range of variation is $L$, its value varies between 5 $\mathrm{mH}$ and $50 \mathrm{mH}$. A clear relation between THD of voltage and $L$ parameter could be observed. With this relation it is concluded that THD of terminal voltage is reflected in the inductance value of the CFL model. The relation is observed in (7).

\subsection{Validation of a CFL model under source voltage variation to harmonic analysis}

The model of the CFL is simulated using the corresponding set of parameters which were estimated in each operating point of the terminal voltage. From each simulation, the corresponding THD of current is obtained. Validation is made comparing both THD of current, from measurements and from simulations of the model with the parameters corresponding to each operating voltage. Simulations are carried on with a pure sinusoidal waveform of the terminal voltage; therefore THD of current obtained in each simulation is produced by the nonlinearity of the CFL without effect from THD of terminal voltage. This situation adds some uncertainty in validation results.

Fig. 8 shows the comparison of THD of current measured and simulated versus 
terminal voltage values. The THD of current obtained from simulations with the DBR model shows the general tendency exhibited by experimental measurements, i.e. an increase in the THD of current occurs when the terminal voltage is increased. This behavior is clear in the range of $35 \mathrm{~V}$ to $100 \mathrm{~V}$. Starting in the latter voltage value the experimental THD of current can be considered constant, with a smooth variation around $110 \%$. In the
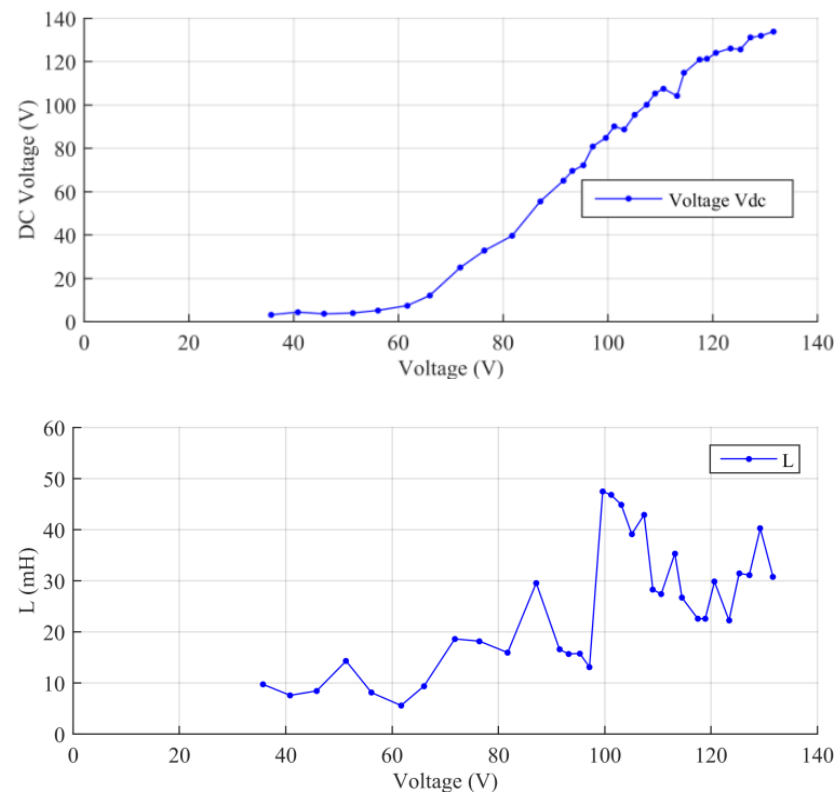

Fig. 7. Value of parameters $V_{d c}, R, L$, and $C$ versus the source terminal voltage. Source: authors

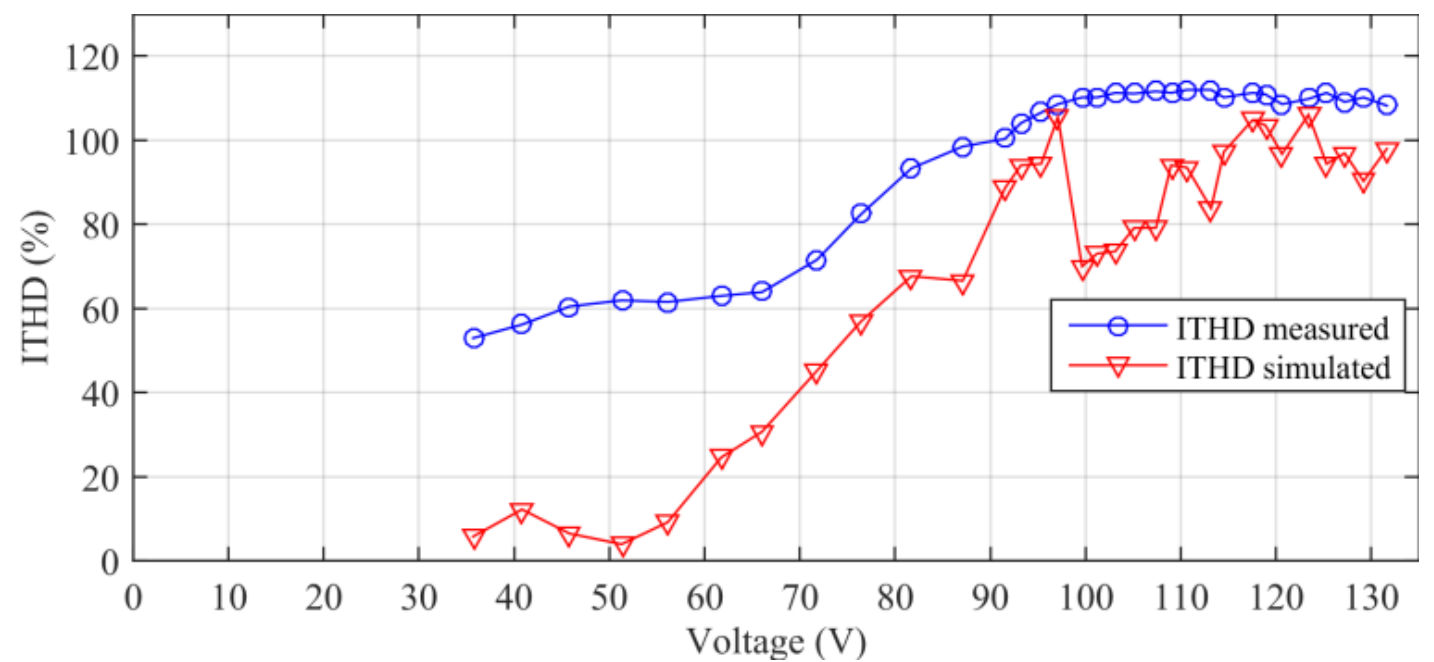

Figure 8. Comparison of measured and simulated total harmonic distortion of current versus the source terminal voltage.

Source: Authors.
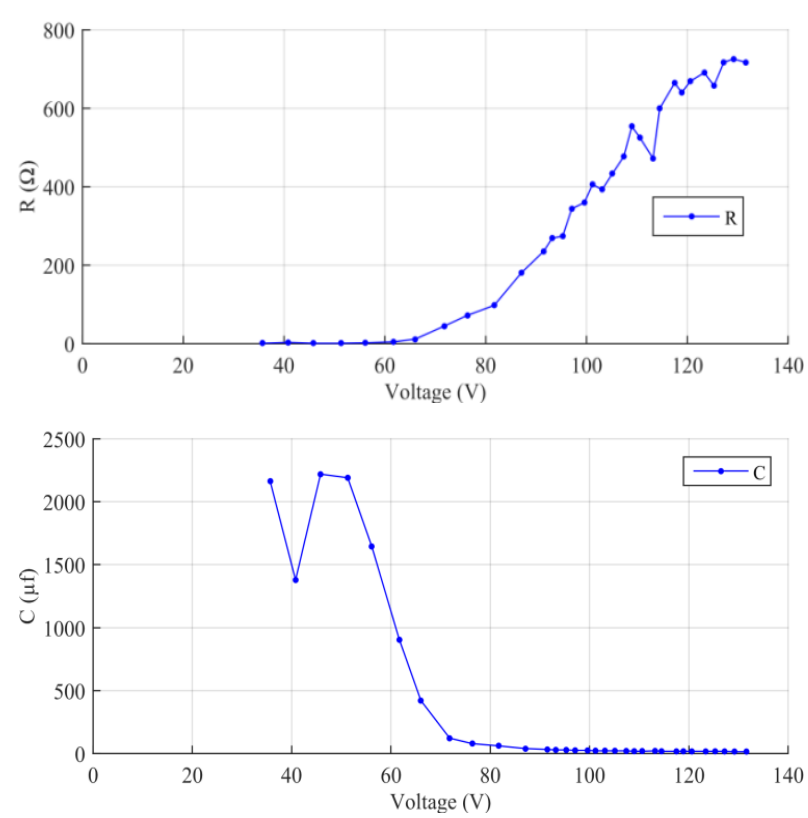

same range of the terminal voltage, $100 \mathrm{~V}$ to $131.6 \mathrm{~V}$, the simulated THD of current values are around $65 \%$ and $108 \%$. Also, an underestimation of the THD of current using the DBR model is observed during the whole range of voltage. The simulated THD of currents corresponding to the voltage values of $98 \mathrm{~V}, 116 \mathrm{~V}, 118 \mathrm{~V}$, and $122 \mathrm{~V}$ are close to the THD of current measured for the same voltage values. From 
Fig. 8 it is concluded that a CFL can be represented with the DBR model for harmonic analysis if the terminal voltage is around $120 \mathrm{~V}$. Big errors will be introduced in the estimation of THD of current if the DBR model is used to represent a CFL in the range of $35 \mathrm{~V}$ and $88 \mathrm{~V}$. A similar situation occurs in the range of $100 \mathrm{~V}$ and 108 $\mathrm{V}$. A validation of the DBR model introducing the harmonics of voltage is necessary to evaluate the scope of the model.

In order to develop a cross validation of the estimated parameters, the following procedure was carried on. The DBR model was simulated using four set of parameters and for each set, the model was feeding with a pure sinusoidal waveform with the rms voltage values used during the experiments. The set of parameters correspond to the lowest voltage $35 \mathrm{~V}$, the rated voltage $120 \mathrm{~V}$, the biggest voltage $130 \mathrm{~V}$, and the voltage where the THD of current from simulation was closer to the experimental THD of current, i.e. 97 V. Fig. 9 shows the comparison of the measured THD of current versus THD of current calculated with the four set of estimated parameters. It can be concluded that simulating a model with one set of parameters and different rms values of the terminal voltage without harmonic components, will result in the same THD of current for all terminal voltages. The THD of current does not depend on the terminal voltage value when the terminal voltage is a pure sinusoid. Because the set of parameters corresponding to $120 \mathrm{~V}$ and $130 \mathrm{~V}$ produce a similar THD of current, Fig. 9 shows two lines close between them.

Because the THD of current is the same for all terminal voltage values, the set of parameters that produces the lowest difference with the measured THD of current in the operation range can be selected to represent the CFL in harmonics analysis, where the terminal voltage varies around the rated voltage. In this case, the set of parameters corresponds to $97 \mathrm{~V}$. Other set of parameters should be selected to obtain the lowest error in the THD of current along the whole range of the terminal voltage evaluated in this work.

Figure 10 shows the comparison of relative errors calculated with two set of parameters. One set corresponds to the rated voltage of the CFL, $120 \mathrm{~V}$, and the other set corresponds to $97 \mathrm{~V}$. If the DBR model is simulated with the parameters estimated in $97 \mathrm{~V}$, the relative error determining the THD of current will be under $6 \%$ in the voltage range of between $94 \mathrm{~V}$ and $131.6 \mathrm{~V}$.

The results reported in Fig. 9 can be compared with results obtained in [3], where a CFL was also powered with a terminal voltage variation. When the validation stage reported in [3] is compared with results reported in Fig. 9, some matches are found. In [3] the authors state that the current waveform of the lamp has been modeled by a mathematical function and in all cases. The adjustments of parameters is accurate, therefore the authors suggests that the model may be used to represent the type of lamp used in the experiments. In this case, the DBR model exhibits small errors in the voltage operation range reported by the manufacturer when the experimental THD of current is compared with the simulated THD. From this comparison is concluded that both models can be used to represent a CFL in the voltage operation range reported by the manufacturer. In [3] the authors report a set of parameters for each terminal voltage value. Here, one set of parameters is suggested to be used to represent a CFL in the whole variation range of voltage reported by the manufacturer. 


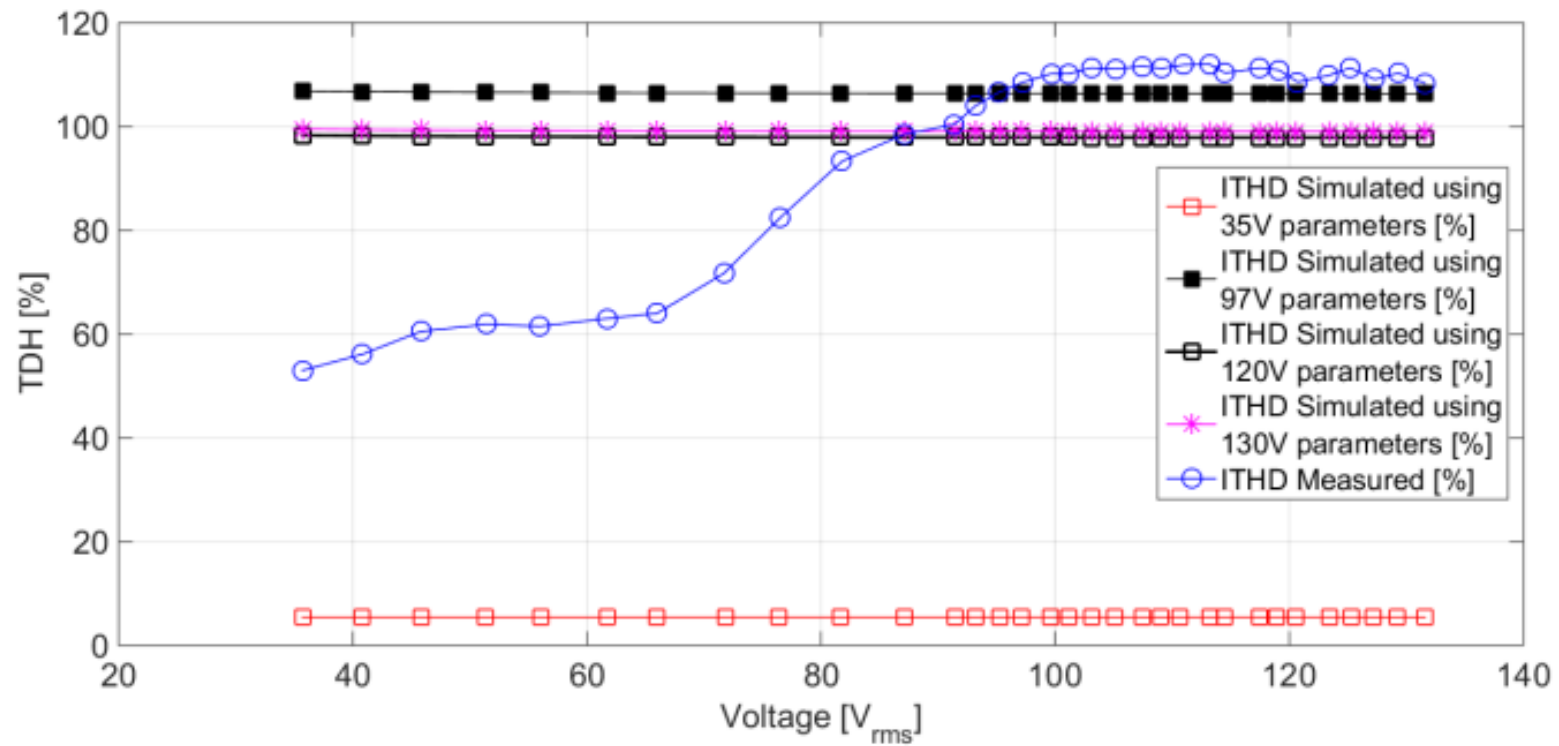

Fig. 9. Comparison of measured and simulated total harmonic distortion of current for four set of parameters.

Source: authors.

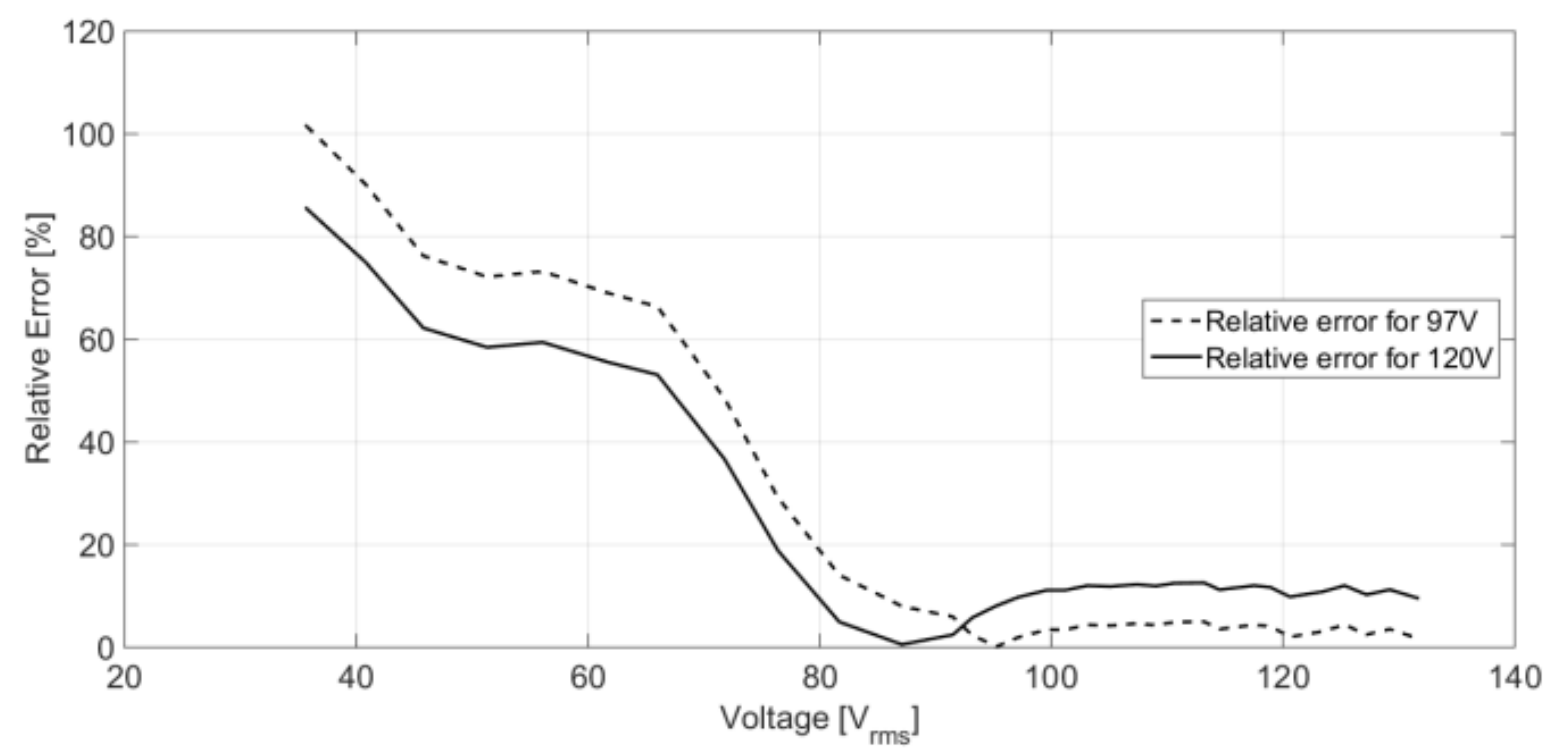

Fig. 10. Comparison of relative errors of measured and simulated total harmonic distortion of current for two set of parameters. Source: authors.

\subsection{Improvements in the stages of the mod- eling process of a CFL}

In this section, several approximations in the modeling process are highlighted to improve the representation of CFLs using the DBR model. First, the selected model is an ideal circuit; see Fig. 1, which does not include some typical elements as snubber protection. Also, several CFL utilize different circuits that could be implemented to represent the specific lamp. However, more detail in the model introduce more computational load.

Other approximation origins in the estimation process, which is graphical-based from an ideal waveforms comparison; see Fig. 2. When the estimation process is 
running the waveforms content harmonics and also noise is present in the signals, introducing challenges in order to register the required magnitudes. A sensibility analysis of model parameters $R, L, C$, and $V_{d c}$ respect to the precision of angles $a, \delta$, and $\gamma_{\max }$, and magnitude $B$ measurements, will define the uncertainties for specific operating conditions of the CFL. Finally, in the validation process, the harmonics components which are present in the experimental terminal voltage should be included in the waveform to simulate the circuit. This uncertainty corresponds to the input of the DBR model and not to the DBR model itself.

\section{CONCLUSIONS}

The modeling of a compact fluorescent lamp for harmonic analysis under terminal voltage variation was presented in this paper. The DBR model was selected to represent the CFL. The methodology to estimate the parameters of the DBR model was presented in detail. This methodology has been widely reported in literature to calculate the parameters of the DBR model. Additionally, an experimental bench was implemented to obtain the measurement required to estimate the parameters. Taking to account the objective of the model, the validation stage consists of a comparison of the THD of current of the experimental signal and the THD of current of the simulated signal using the DBR model.

The CFL evaluated can be represented with the DBR model and one set of parameters. It is possible to choose the set of parameters that produce the lowest error in THD of current, in the range of voltage operation suggested by the manufacturer. Other set of parameters can be selected to obtain a better representation in the range of voltage operation proposed in this work. Future work is presented in order to reduce the uncertainties during the modeling process. Sensibility analysis of the parame- ters with respect to graphical measurements is required. Also, new simulations including the harmonic components of the terminal voltage will increase the scope of the results presented in this paper.

\section{ACKNOWLEDGMENTS}

This work was supported by Universidad Nacional de Colombia and COLCIENCIAS (Fondo nacional de financiamiento para la ciencia, la tecnología y la innovación Francisco José de Caldas) under the project MicroRENIZ-25439 with Code 1118-669- 46197.

\section{REFERENCES}

[1] J. Drapela, R. Langella, J. Slezingr, and A. Testa, "Generalized lamp model for light flicker studies," Electr. Power Syst. Res., vol. 154, pp. 413-422, Jan. 2018.

[2] A. C. Henao-Munoz and A. J. SaavedraMontes, "Comparison of two mathematical models for nonlinear residential loads," in 2016 17th International Conference on Harmonics and Quality of Power (ICHQP), 2016, pp. 1-6.

[3] J. Cunill-Sola and M. Salichs, "Study and Characterization of Waveforms From LowWatt $(<25 \mathrm{~W})$ Compact Fluorescent Lamps With Electronic Ballasts," IEEE Trans. Power Deliv., vol. 22, no. 4, pp. 2305-2311, Oct. 2007.

[4] C. Jiang, D. Salles, W. Xu, and W. Freitas, "Assessing the Collective Harmonic Impact of Modern Residential Loads-Part II: Applications," IEEE Trans. Power Deliv., vol. 27, no. 4, pp. 1947-1955, Oct. 2012.

[5] N. R. Watson, T. L. Scott, and S. Hirsch, "Implications for Distribution Networks of High Penetration of Compact Fluorescent Lamps," IEEE Trans. Power Deliv., vol. 24, no. 3, pp. 1521-1528, Jul. 2009.

[6] Z. Radakovic, F. V Topalis, and M. Kostic, "The voltage distortion in low-voltage networks caused by compact fluorescent lamps with electronic gear," Electr. Power Syst. Res., vol. 73, no. 2, pp. 129-136, Feb. 2005.

[7] S. M. Shyni, M. W. Abitha, and C. Bhuvaneswari, "Power factor improvement of compact fluorescent lightings with valleyfill circuit," in 2017 International Conference 
Experimental characterization of compact fluorescent lamps for harmonic analysis of power distribution systems

on Computation of Power, Energy Information and Commuincation (ICCPEIC), 2017, pp. 622-626.

[8] Y. Babacan, C. P. Uzunoğlu, S. Cekli, F. Kaçar, and M. Uğur, "Wavelet analysis of a memristor emulated model proposed for compact fluorescent lamp operated systems," Electr. Power Syst. Res., vol. 160, pp. 56-62, Jul. 2018.

[9] J. Molina and L. Sainz, "Compact Fluorescent Lamp Modeling for Large-Scale Harmonic Penetration Studies," IEEE Trans. Power Deliv., vol. 30, no. 3, pp. 1523-1531, Jun. 2015.

[10] J. Molina and L. Sainz, "Model of Electronic Ballast Compact Fluorescent Lamps," IEEE Trans. Power Deliv., vol. 29, no. 3, pp. 13631371, Jun. 2014.

[11] J. Yong, L. Chen, A. B. Nassif, and W. Xu, "A Frequency-Domain Harmonic Model for Compact Fluorescent Lamps," IEEE Trans. Power Deliv., vol. 25, no. 2, pp. 1182-1189, Apr. 2010.

[12] A. B. Nassif and Wilsun Xu, "Characterizing the Harmonic Attenuation Effect of Compact Fluorescent Lamps," IEEE Trans. Power Deliv., vol. 24, no. 3, pp. 1748-1749, Jul. 2009.

[13] J. Molina, J. J. Mesas, and L. Sainz, "Parameter estimation procedure for the equivalent circuit model of compact fluorescent lamps," Electr. Power Syst. Res., vol. 116, pp. 128-135, Nov. 2014.

[14] L. Sainz, J. Cunill, and J. J. Mesas, "Parameter estimation procedures for compact fluorescent lamps with electronic ballasts," Electr. Power Syst. Res., vol. 95, pp. 77-84, Feb. 2013.

[15] G. Malagon-Carvajal, C. Duarte, G. OrdonezPlata, C. F. M. Almeida, and N. Kagan, "Harmonic attenuation-amplification effect on lighting branch circuits," in 2017 IEEE 6th International Conference on Renewable Energy Research and Applications (ICRERA), 2017, pp. 283-289.

[16] F. V. Topalis, I. F. Gonos, and G. A. Vokas, "Arbitrary waveform generator for harmonic distortion tests on compact fluorescent lamps," Measurement, vol. 30, no. 4, pp. 257267, Dec. 2001.

[17] Mok Yan Kit, W. H. Lau, and C. F. N. Tse, "A study on the effects of voltage distortion on current harmonics generated by modern smps driven home appliances in smart grid network," in 9th IET International Conference on Advances in Power System Control, Operation and Management (APSCOM 2012), 2012, pp. 85-85.

[18] J. Yong, L. Chen, and S. Chen, "Modeling of Home Appliances for Power Distribution System Harmonic Analysis," IEEE Trans. Power Deliv., vol. 25, no. 4, pp. 3147-3155, Oct. 2010. 